\title{
Persistence of Mycoplasma synoviae in hens after two enrofloxacin treatments and detection of mutations in the parC gene
}

\author{
Jérôme LE CARROU, Anita K. REINHARDT, Isabelle KEMPF, \\ Anne V. GAUTIER-BOUCHARDON* \\ Agence Française de Sécurité Sanitaire des Aliments, Laboratoire d'Études et de Recherches Avicoles \\ et Porcines, Unité de Mycoplasmologie-Bactériologie, BP 53, 22440 Ploufragan, France
}

(Received 11 April 2005; accepted 12 July 2005)

\begin{abstract}
The ability of Mycoplasma synoviae, an avian pathogen, to persist despite fluoroquinolone treatments was investigated in hens. Groups of Mycoplasma-free hens were experimentally infected with the $M$. synoviae 317 strain and treated twice with enrofloxacin at the therapeutic dose. The results show that the two treatments did not have any influence on this strain of M. synoviae recovery from tracheal swabs. Mycoplasmas were isolated from tracheal swab cultures, but not from inner organs such as the liver or spleen, suggesting that this strain of $M$. synoviae was not able to cross the mucosal barrier to disseminate throughout the host. A significant increase of the resistance level to enrofloxacin of five re-isolated mycoplasma clones, was observed after the second treatment. This increase was associated in two clones to a Ser81 $\rightarrow$ Pro substitution, found in the ParC quinolone-resistance determining region (QRDR) of DNA topoisomerase IV. This is the first time that a mutation in a gene coding for topoisomerase IV is described in M. synoviae after in vivo enrofloxacin treatments in experimentally infected hens.
\end{abstract}

Mycoplasma synoviae / fluoroquinolone / persistence / topoisomerase / poultry

\section{INTRODUCTION}

Mycoplasma synoviae infection most frequently occurs as a subclinical upper respiratory infection and is sometimes responsible for infectious synovitis in broilers and turkeys [22]. M. synoviae in association with Escherichia coli can also cause Chronic Respiratory Disease (CRD) [36]. The economic consequences may be important because of decreased egg production, growth retardation, and condemnation at slaughter due to airsacculitis, synovitis and arthritis lesions. M. synoviae may be transmitted either vertically, through the eggs, or laterally, by direct contact or via the environment $[22,25]$. M. synoviae is susceptible to various antibiotics in vitro, including tetracyclines, macrolides (except erythromycin) and fluoroquinolones [7, 15]. However, although antibiotic treatments decrease the symptoms, they do not eliminate $M$. synoviae infections [22]. Moreover, $M$. synoviae isolates displaying increased enrofloxacin MIC have been isolated [37] and development of resistant $M$. synoviae strains has been observed in vitro [15]. In France, enrofloxacin $\left(\right.$ Baytril $\left.^{\circledR} 10 \%\right)$ is approved for the

\footnotetext{
* Corresponding author: a.bouchardon@ploufragan.afssa.fr
} 
treatment of respiratory infections associated with $M$. synoviae or $M$. gallisepticum and for the treatment of colibacillosis in hens or broiler chickens. M. synoviae strains might be in contact with enrofloxacin not only when hens are treated for respiratory infections but also when they are treated for colibacillosis. Under field conditions, repeated treatments with fluoroquinolones can be administered to breeder hens and turkeys. Fluoroquinolone resistance mechanisms might be selected during these treatments and may result in therapeutic failures.

The main targets of fluoroquinolones are replication and transcription enzymes, i.e. DNA gyrase and topoisomerase IV, which both are essential for bacterial viability [26]. Most reported mutations involved in fluoroquinolone resistance are concentrated in the quinolone resistance determining regions (QRDR) of the $g y r A / g y r B$ and parC/parE genes of DNA gyrase and topoisomerase IV, respectively [29, 31, 32].

The present study describes the effect of two enrofloxacin treatments on $M$. synoviae infection in experimentally infected hens and the emergence of resistant mycoplasmas.

\section{MATERIALS AND METHODS}

\subsection{Bacterial strains}

M. synoviae 317 and M. synoviae 86122 , two field strains isolated from a turkey trachea and from cockerel air sacs, respectively, and $M$. synoviae WVU 1853, a reference strain, were grown in FM4 broth and plated on an FM4 agar medium [14]. The titer of $M$. synoviae was expressed as Colony Forming Units per milliliter (CFU/ $\mathrm{mL}$ ). The M. synoviae 317 strain used for experimental infection was susceptible to enrofloxacin in vitro (minimum inhibitory concentration $(\mathrm{MIC})=0.25 \mu \mathrm{g} / \mathrm{mL}$ ) [20].

\subsection{Antimicrobial agents}

Baytril $^{\circledR} 10 \%$ (enrofloxacin oral solution) was used for treatment in drinking water.
Enrofloxacin for MIC determinations was kindly provided by Bayer Pharma (Puteaux, France).

\subsection{Experimental infection}

Thirty eleven-week-old mycoplasmafree hens were obtained from Hubbard (Le Foeil, France). The birds were maintained in cages in isolated facilities of the Experimental Poultry Unit of AFSSA (Ploufragan, France). Prior to infection (day 0), tracheal swabs and blood samples were collected from 10 randomly selected animals. Hens were exposed to aerosol generated with $10^{6}$ UFC of $M$. synoviae 317 strain per millilitre in a nebulizer (Atomist $100 \mathrm{E}$, CEVA, Libourne, France). Exposure lasted for $10 \mathrm{~min}$ (volume of the room: $70 \mathrm{~m}^{3}$ ) with a nebulizer air flow of $50 \mathrm{~mL} / \mathrm{min}$. On day 7 post-infection (PI), tracheal swabs were collected from each animal. On day 21 , ten randomly chosen animals were removed to another room and served as infected untreated controls. The twenty remaining hens were maintained in the room where the inoculation had been performed.

\subsection{Treatment via the drinking water}

Three weeks after infection (day $23 \mathrm{PI}$ ), a first medication with enrofloxacin (Baytril ${ }^{\circledR} 10 \%$ ) at the therapeutic dose (TD = $10 \mathrm{mg} / \mathrm{kg}$ of body weight/day) was given for five consecutive days (from day 23 to day 27) in the drinking water to the 20 infected treated hens. One week after the end of the first medication, a second treatment was similarly administered (from day 36 to day 40). Antibiotic doses were calculated daily, based on daily water consumption rates and body weight of birds.

\subsection{Samples and mycoplasma cultures}

Tracheal swabs were collected from all birds on days 23, 28, 36 and 41 postinfection. Five infected treated birds were humanely killed before and after each treatment and examined post-mortem for gross lesions; five untreated birds were sacrificed 
in the same conditions after the first and second treatments, on days 28 and 41 . Tissue samples (trachea, lung, air sacs, liver, spleen and ovaries) were collected for mycoplasma cultures.

All tracheal swabs were placed in $2 \mathrm{~mL}$ of transport medium ( $2 \%$ buffered peptone water containing glycerol $(1.2 \% \mathrm{vol} / \mathrm{vol})$, amphotericin B: $2.5 \mu \mathrm{g} / \mathrm{mL}$, ampicillin: $100 \mu \mathrm{g} / \mathrm{mL}$ and colistin: $7.5 \mu \mathrm{g} / \mathrm{mL}$ ). Mycoplasmas were cultured from tracheal swabs by diluting $100 \mu \mathrm{L}$ of transport medium from each swab in $900 \mu \mathrm{L}$ of FM4 broth [14] (initial suspension). Tissue samples were diluted 1/10 in FM4 broth medium (wt/vol) and homogenized by using a Stomacher (AES, Combourg, France) (initial suspension).

Serial ten-fold dilutions up to $10^{-4}$ of initial suspensions were prepared and incubated at $37{ }^{\circ} \mathrm{C}$ until the culture developed an acid color change or up to 30 days. When a color change of the broth medium was observed, the uncloned cultures were aliquoted and stored at $-70{ }^{\circ} \mathrm{C}$ before MIC determinations.

Since these cultures could contain mixtures of wild and mutant cells, some cultures, obtained from one bird before or after the first treatment, or from three birds after the second treatment, were cloned. Cultures of M. synoviae were grown on Frey agar medium [13]: single colonies were taken under a microscope with a sterile yellow tip (Corning Incorporated, NY, USA) and were multiplied in $1 \mathrm{~mL}$ of Frey broth medium. The 16 resulting clones were aliquoted and stored at $-70{ }^{\circ} \mathrm{C}$.

\subsection{Determination of MIC}

The enrofloxacin MIC of the mycoplasma isolates were determined by a metabolic inhibition method performed in Frey broth medium [13] in 96-well microtiter plates as previously described [2]. Enrofloxacin concentrations ranged from 0.03 to $32 \mu \mathrm{g} / \mathrm{mL}$. MIC was defined as the lowest concentration for which no visible growth was observed when a color change was observed in control cultures without antibiotic.
MIC were determined on mycoplasma cultures and on the 16 clones.

\subsection{Serology}

The presence of antibodies directed against $M$. synoviae in blood samples was checked using a slide agglutination (SA) test with a commercial antigen (Nobilis ${ }^{\circledR}$ MS Antigen, Intervet International B.V., Boxmeer, Holland) [19].

\subsection{Amplification of the Quinolone Resistance-Determining Regions (QRDR) of topoisomerases}

DNA from M. synoviae WVU 1853 , M. synoviae 86122 and the 16 clones of M. synoviae 317 strain, were prepared according to standard methods [18]. Since the QRDR of the gyrA and gyrB genes of DNA gyrase and the parC and parE genes encoding for topoisomerase IV were not available for $M$. synoviae, amplification of the QRDR of $g y r A$ and $g y r B$ were performed with primers previously chosen from the nucleotide sequence of M. gallisepticum S6 strain [12]. Amplifications of parC and parE of the $M$. synoviae 317 strain, were initially performed with primers chosen from M. gallisepticum [31, 32]. The nucleotide sequences obtained were then used to determine new internal specific primers (Tab. I). PCR were performed with a Perkin-Elmer 2400 thermal cycler (Tab. II). PCR products obtained for gyrA and parC were purified with the Qiaquick ${ }^{\circledR}$ PCR purification kit (Qiagen, Courtabœuf, France) following manufacturer recommendations. Specific and non-specific PCR products were obtained for gyrB and parE. The specific products were purified with the Qiaquick ${ }^{\circledR}$ gel purification kit (Qiagen) following manufacturer recommendations.

\subsection{DNA sequencing and sequence analysis}

All purified PCR products were sequenced directly on both strands using an ABI Prism AmpliTaq FS, DyeDeoxy-Terminator kit 
Table I. Primers for amplification of M. synoviae gyrA, gyrB, parC and parE QRDR.

\begin{tabular}{|c|c|c|c|}
\hline Gene & Primers & Sequences & PCR Fragment length (bp) \\
\hline gyrA & GyrAs1/GyrAi1 & $\begin{array}{l}\text { 5'-GATGGWTTRAARCCWGTWCAY-3' } \\
\text { 5'-TTGWATATTWGTWGCCATWCC-3' }\end{array}$ & 436 \\
\hline gyrB & $\mathrm{MsBs} 2 / \mathrm{MsBi} 2$ & $\begin{array}{l}\text { 5'-CCTCAATATGAAGGTCAAAC-3' } \\
\text { 5'-CCTAAACCTTTATAGCGTTG-3' }\end{array}$ & 457 \\
\hline $\operatorname{parC}$ & MSPARC4/MSPARC2 & $\begin{array}{l}\text { 5'-TTTGTACTCAATGTGAATGT-3' } \\
\text { 5'-TATCTGTAGCAAAACCTGAA-3' }\end{array}$ & 544 \\
\hline parE & MSparE7/MSparE5 & $\begin{array}{l}\text { 5'-ACCCCAGCTCAACAAAAA-3' } \\
\text { 5'-AACTGTTCTCAGTTCATC-3' }\end{array}$ & 458 \\
\hline
\end{tabular}

Table II. PCR conditions used for $M$. synoviae QRDR amplifications. Reactions were performed in a total volume of $50 \mu \mathrm{L}$ using the Platinum Taq polymerase.

\begin{tabular}{lccccc}
\hline & PCR & gyrA & gyrB & parC & parE \\
\hline \multirow{4}{*}{ Programs } & Denaturation & $95^{\circ} \mathrm{C}, 5 \mathrm{~min}$ & $95^{\circ} \mathrm{C}, 5 \mathrm{~min}$ & $95^{\circ} \mathrm{C}, 5 \mathrm{~min}$ & $95^{\circ} \mathrm{C}, 5 \mathrm{~min}$ \\
& Denaturation & $95^{\circ} \mathrm{C}, 15 \mathrm{~s}$ & $95^{\circ} \mathrm{C}, 15 \mathrm{~s}$ & $95^{\circ} \mathrm{C}, 15 \mathrm{~s}$ & $95^{\circ} \mathrm{C}, 15 \mathrm{~s}$ \\
& Annealing & $48^{\circ} \mathrm{C}, 40 \mathrm{~s}$ & $52^{\circ} \mathrm{C}, 50 \mathrm{~s}$ & $48{ }^{\circ} \mathrm{C}, 30 \mathrm{~s}$ & $52^{\circ} \mathrm{C}, 30 \mathrm{~s}$ \\
& Extension & $72{ }^{\circ} \mathrm{C}, 45 \mathrm{~s}$ & $72{ }^{\circ} \mathrm{C}, 45 \mathrm{~s}$ & $72{ }^{\circ} \mathrm{C}, 30 \mathrm{~s}$ & $72{ }^{\circ} \mathrm{C}, 30 \mathrm{~s}$ \\
& Cycle number & 45 & 45 & 45 & 45 \\
Mix & Extension & $72{ }^{\circ} \mathrm{C}, 5 \mathrm{~min}$ & $72{ }^{\circ} \mathrm{C}, 5 \mathrm{~min}$ & $72{ }^{\circ} \mathrm{C}, 5 \mathrm{~min}$ & $72{ }^{\circ} \mathrm{C}, 5 \mathrm{~min}$ \\
conditions & Buffer $10 \mathrm{X}$ & $5 \mu \mathrm{L}$ & $5 \mu \mathrm{L}$ & $5 \mu \mathrm{L}$ & $5 \mu \mathrm{L}$ \\
& MgCl2 & $2 \mathrm{mM}$ & $4 \mathrm{mM}$ & $2.5 \mathrm{mM}$ & $2.5 \mathrm{mM}$ \\
& dNTP & $200 \mu \mathrm{M}$ & $200 \mu \mathrm{M}$ & $200 \mu \mathrm{M}$ & $200 \mu \mathrm{M}$ \\
& Primers & $0.2 \mu \mathrm{M}$ & $0.2 \mu \mathrm{M}$ & $0.2 \mu \mathrm{M}$ & $0.2 \mu \mathrm{M}$ \\
\hline
\end{tabular}

in an ABI PRISM 373A sequencer (Perkin Elmer). The QRDR sequences obtained were compared to databanks using the Network Protein Sequence Analysis software [9].

\subsection{Nucleotide sequence accession numbers}

The nucleotide sequences of $M$. synoviae 317 strain gyrA, gyrB, parC and parE QRDR are in the GenBank nucleotide sequence database under accession no. AY819793 (gyrA), AY819794 (gyrB), AY819792 (parC) and AY819795 (parE), respectively. The nucleotide sequences of M. synoviae WVU 1853 and 86122 strains parC QRDR are in the GenBank nucleotide sequence database under accession no. AY819796 and AY819797, respectively.
QRDR sequences of $M$. synoviae were compared to homologous sequences of $M$. hominis [4, 6, 24], M. pulmonis [8], M. gallisepticum [28] and E. coli [40].

\subsection{Statistical analysis}

The SAS system [34] was used to compare MIC results with the Student-NewmanKeuls test. Differences were estimated significant when $p<0.05$.

\section{RESULTS}

\subsection{Persistence of $M$. synoviae after two enrofloxacin treatments}

$M$. synoviae was recovered from all tracheal swabs as well as all tracheal cultures 
Table III. Re-isolation of M. synoviae and susceptibility levels of M. synoviae uncloned cultures before and after two successive treatments with enrofloxacin.

\begin{tabular}{|c|c|c|c|c|}
\hline & \multicolumn{2}{|c|}{ Number of positive hens } & \multicolumn{2}{|c|}{$\mathrm{MIC}_{\mathrm{ENRO}}{ }^{\mathrm{c}}$ of MS cultures $(\mu \mathrm{g} / \mathrm{mL})$} \\
\hline & Treated & Untreated & Treated & Untreated \\
\hline $\begin{array}{l}\text { Before } \mathrm{T} 1^{\mathrm{a}} \\
(\text { Day } 23)\end{array}$ & $20 / 20$ & ND & $\begin{array}{c}0.25-0.5^{\mathrm{d}} \\
(0.46)^{\mathrm{e}}\end{array}$ & ND \\
\hline $\begin{array}{l}\text { After T1 } \\
\text { (Day 28) }\end{array}$ & $15 / 15$ & $10 / 10$ & $\begin{array}{c}0.25-1 \\
(0.50)\end{array}$ & $\begin{array}{c}0.25-0.5 \\
(0.46)\end{array}$ \\
\hline $\begin{array}{l}\text { Before } \mathrm{T} 2^{\mathrm{b}} \\
\text { (Day 36) }\end{array}$ & $10 / 10$ & ND & $\begin{array}{c}0.25-0.5 \\
(0.42)\end{array}$ & ND \\
\hline $\begin{array}{l}\text { After T2 } \\
\text { (Day 41) }\end{array}$ & $5 / 5$ & $5 / 5$ & $\begin{array}{c}1-2 \\
(1.40)^{*}\end{array}$ & $\begin{array}{c}0.25-1 \\
(0.53)\end{array}$ \\
\hline
\end{tabular}

${ }^{\mathrm{a}}$ First treatment; ${ }^{\mathrm{b}}$ second treatment; ${ }^{\mathrm{c}}$ minimum inhibitory concentration of enrofloxacin; ${ }^{\mathrm{d}}$ MIC range;

${ }^{\mathrm{e}}$ MIC geometric mean. ND: not determined.

* Significantly different from the five other groups of cultures $(p<0.05)$.

after the first and after the second treatment (Tab. III). No mycoplasma could be re-isolated from inner organs (lung, air sacs, liver, spleen and ovaries) or from blood (data not shown). Furthermore, no significant difference in the number of re-isolated mycoplasmas was observed between the cultures from tracheal swabs collected before and after the treatments, or between the cultures from treated and untreated birds (data not shown): all the dilutions (up to $10^{-4}$ ) developed an acid color change within one week for untreated or treated hens.

\subsection{Increase of enrofloxacin MIC}

The results of MIC determination did not show any significant difference between the susceptibility to enrofloxacin of the M. synoviae uncloned cultures recovered after the first treatment or before the second treatment and the wild-type strain (Tab. III). However, a small but significant increase of the resistance level to enrofloxacin was observed after the second treatment (MIC = $1-2 \mu \mathrm{g} / \mathrm{mL})$ compared to the initial MIC $(0.25-0.5 \mu \mathrm{g} / \mathrm{mL})(p<0.05)$.

Enrofloxacin MIC were also determined on clones isolated before and after the first and second treatments (Tab. IV). As for the $M$. synoviae uncloned suspensions, these results clearly pointed out an increase in the MIC after the second treatment for all but one $M$. synoviae clones, with values ranging from 0.5 to $4 \mu \mathrm{g} / \mathrm{mL}$ of enrofloxacin.

\subsection{Analysis of the gyrA, gyrB, parC and parE QRDR of $M$. synoviae}

The GyrA, GyrB and ParE QRDR amino acid sequences deduced from DNA sequences of the M. synoviae 317 strain were found to share $100 \%$ of identity with those of two other M. synoviae strains: the M. synoviae WVU1853 reference strain and the M. synoviae 86122 field strain (data not shown). The ParC amino acid sequence of M. synoviae 317 shared $72.5 \%$ of identity with M. synoviae 86122 and M. synoviae WVU 1853 (data not shown). The GyrA, GyrB and ParC sequences of the M. synoviae 317 strain shared a higher degree of identity with those of Mycoplasma pulmonis and Mycoplasma hominis, than with those of M. gallisepticum, another avian mycoplasma (Tab. V). The ParE amino acid sequence of the M. synoviae 317, M. synoviae WVU 1853 , and $M$. synoviae 86122 strains shared $100 \%$ identity with the ParE QRDR of the M. gallisepticum strain.

The gyrA, gyrB, parC and parE QRDR were characterized for six clones presenting 
Table IV. Susceptibility levels and mutations detected in clones of $M$. synoviae before and after two successive treatments with enrofloxacin.

\begin{tabular}{|c|c|c|c|c|}
\hline & $\begin{array}{l}\text { Number } \\
\text { of clones } \\
\text { analyzed }\end{array}$ & & $\begin{array}{c}\text { MIC }_{\text {ENRO }^{c}} \\
(\mu \mathrm{g} / \mathrm{mL})\end{array}$ & $\begin{array}{c}\text { Mutations } \\
\text { in QRDR } \\
\text { of ParC } 81^{\mathrm{d}}\end{array}$ \\
\hline MS 317 & 1 & - & 0.25 & Ser \\
\hline \multicolumn{5}{|l|}{ Wild type } \\
\hline \multirow[t]{5}{*}{ Before $\mathrm{T} 1^{\mathrm{a}}$} & 5 & Bird 1 & 0.25 & \\
\hline & & & 0.25 & \\
\hline & & & 0.5 & ND \\
\hline & & & 0.5 & \\
\hline & & & 0.25 & \\
\hline \multirow{5}{*}{$\begin{array}{l}\text { After } \mathrm{T} 1 \text { and } \\
\text { before } \mathrm{T} 2^{\mathrm{b}}\end{array}$} & 5 & Bird 2 & 0.5 & \\
\hline & & & 0.5 & \\
\hline & & & 0.5 & ND \\
\hline & & & 0.5 & \\
\hline & & & 0.25 & \\
\hline \multirow[t]{6}{*}{ After T2 } & 6 & Bird 3 & 0.5 & Ser \\
\hline & & & 1 & Ser \\
\hline & & Bird 4 & 1 & Pro \\
\hline & & & $1-2$ & Pro \\
\hline & & & 4 & Ser \\
\hline & & Bird 5 & 2 & Ser \\
\hline
\end{tabular}

${ }^{a}$ First treatment; ${ }^{b}$ second treatment; ${ }^{\mathrm{c}}$ minimum inhibitory concentration of enrofloxacin; ${ }^{\mathrm{d}}$ position of the mutation, E. coli numbering. ND: not determined.

an enrofloxacin MIC increase (Tab. IV). No mutation could be detected in the QRDR of the $g y r A, g y r B$ and parE genes for any of the clones. A Ser81 $\rightarrow$ Pro substitution (E. coli numbering) was found in the ParC QRDR of the DNA topoisomerase IV of two clones isolated from the same bird and displaying a 2-4 fold increase of the enrofloxacin MIC (1-2 $\mu \mathrm{g} / \mathrm{mL})$ (Tab. IV). The third clone isolated from this bird, displaying the highest MIC $(4 \mu \mathrm{g} / \mathrm{mL})$, did not present any mutation in the QRDR of the topoisomerase genes. One clone (MIC = $1 \mu \mathrm{g} / \mathrm{mL}$ ) had two mutations in $\operatorname{parC}$ without consequences on the amino acid sequence (data not shown). No mutation could be detected in the QRDR of the last two clones $(\mathrm{MIC}=0.5$ and $2 \mu \mathrm{g} / \mathrm{mL})(\mathrm{Tab} . \mathrm{IV})$.

\section{DISCUSSION}

Two successive treatments at the therapeutic dose of enrofloxacin did not have any influence on the $M$. synoviae recovery from tracheal swabs, with $100 \%$ of the hens still positive up to the $10^{-4}$ dilution after the second treatment. Although M. synoviae is susceptible in vitro to various antibiotics including enrofloxacin [7, 20], persistence after antimicrobial treatments is regularly observed in field conditions $[22,35]$. This phenomenon has already been described for $M$. gallisepticum in chickens [33], but successive treatments at the therapeutic dose reduced the percentage of $M$. gallisepticum-infected birds. This difference might be explained by the lower susceptibility to enrofloxacin of $M$. synoviae 317 strain $(0.25 \mu \mathrm{g} / \mathrm{mL})$ in comparison with the $M$. gallisepticum 4191 strain $(0.06 \mu \mathrm{g} / \mathrm{mL})$ [31]. Moreover, treatment on $M$. synoviae-infected birds

Table V. Sequence identities between the M. synoviae GyrA, GyrB, ParC and ParE QRDR of the M. synoviae 317 strain and homologous GyrA, GyrB, ParC and ParE QRDR from various species.

\begin{tabular}{|c|c|c|c|c|c|c|c|c|c|c|}
\hline \multirow{3}{*}{$\begin{array}{l}\text { M. synoviae } \\
317 \text { strain }\end{array}$} & \multicolumn{10}{|c|}{$\%$ of amino acid identity } \\
\hline & \multicolumn{2}{|c|}{ M. pulmonis } & \multicolumn{3}{|c|}{ M. hominis } & \multicolumn{2}{|c|}{ M. gallisepticum } & \multicolumn{3}{|c|}{ E. coli } \\
\hline & GyrA GyrB P & ParC ParE & GyrA GyrB & ParC & ParE & GyrA GyrB & ParC ParE & GyrA GyrB & ParC F & ParE \\
\hline GyrA & 90 & & 90 & & & 67.5 & & 72.5 & & \\
\hline GyrB & 90.9 & & 86.4 & & & 77.3 & & 77.3 & & \\
\hline ParC & & 77.5 & & 67.5 & & & 57.5 & & 52.5 & \\
\hline ParE & & 86.3 & & & 72.8 & & 100 & & & 63.6 \\
\hline
\end{tabular}


was performed three weeks after inoculation, on a well established infection, whereas treatments on $M$. gallisepticum-infected chickens were performed one or two weeks after inoculation. Stanley et al. [35] also showed that, under field conditions, enrofloxacin is less efficacious on $M$. synoviae than on M. gallisepticum.

In chickens, enrofloxacin is highly and rapidly absorbed after continuous medication at the therapeutic dose via drinking water as indicated by a high bioavailibility $(89 \%)$ and steady-state plasma concentration of enrofloxacin $(0.52 \mu \mathrm{g} / \mathrm{mL})$ [23]. More interestingly, high antimicrobial concentrations are attained in the trachea $(1.57 \mu \mathrm{g} / \mathrm{mL})$ and lungs $(0.88 \mu \mathrm{g} / \mathrm{mL})$. These concentrations are 3-6 fold higher than $M$. synoviae strain $317 \mathrm{MIC}$ for enrofloxacin $(0.25 \mu \mathrm{g} / \mathrm{mL})$, so that better issue of the treatment was expected.

Several hypotheses to explain M. synoviae persistence in the treated birds include the following: (i) the possible development of resistance mechanisms as described in vitro [15]; (ii) survival on materials in the animal environment [25] and subsequent natural re-infection of birds; (iii) ability to invade host cells for long periods and reach subcellular fractions where enrofloxacin would not be active or to persist inside the cell [27, 39] in a fluoroquinolone-insensitive state, as described for M. penetrans [10]. The presence of a non- or slow-dividing subpopulation named "persisters", as previously described for different bacterial species, may be linked with $M$. synoviae persistence $[1,21]$. Persistence observed in this study cannot be explained by dissemination of mycoplasmas in inner organs such as the liver, spleen or ovaries. Re-infection of birds from the environment after treatments could not explain the $M$. synoviae persistence in this study: tracheal swab cultures were still positive up to the $10^{-4}$ dilutions immediately after the treatment.

To our knowledge, this is the first time that such a decrease in susceptibility of M. synoviae isolates is clearly described after an in vivo treatment with enrofloxacin. Stanley et al. [35] found a M. synoviae isolate with an intermediate to resistant level during a treatment with enrofloxacin, but its susceptibility level was not determined before the treatment. It would have been interesting to know if enrofloxacin medication could be responsible for the intermediate to resistant level of this $M$. synoviae isolate. Persistence has also been previously described for M. gallisepticum but no significant MIC change was observed after several treatments [33].

The development of resistance in $M$. synoviae and M. gallisepticum has already been described in vitro [15]. However, this is the first time that such an increase of resistance, associated to a ParC Ser81 $\rightarrow$ Pro, is described after two in vivo treatments at the therapeutic dose. This ParC substitution was also found in quinolone-resistant mutants of M. gallisepticum obtained in vitro [31, 32], or in clinical isolates of M. hominis [5] and Staphylococcus aureus [38]. Our results are in accordance with those previously obtained for $M$. gallisepticum, where the ParC Ser81 $\rightarrow$ Pro substitution was associated with a 2-4 fold increase of the enrofloxacin MIC [32]. Mycoplasma cultures obtained after the second treatment were heterogeneous with clones presenting different susceptibility levels and parC sequences.

The M. synoviae 317 and WVU1853 strains are less susceptible to enrofloxacin ( $\mathrm{MIC}=0.25$ and $0.5 \mu \mathrm{g} / \mathrm{mL}$, respectively) than the M. gallisepticum ATCC 15302 and 41-91 strains $(\mathrm{MIC}=0.03$ and $0.06 \mu \mathrm{g} / \mathrm{mL}$, respectively) [31]. Differences in the amino acid sequences of the genes coding for topoisomerases might explain in part the differences in enrofloxacin susceptibility between the two species. In the GyrA QRDR of all M. synoviae strains sequenced, an Asn was found at position 87 instead of a Glu. A Glu87 $\rightarrow$ Asn substitution has never been described in $M$. gallisepticum. Nevertheless, an Asp has been found in many bacterial species at position 87 of GyrA and the Asp87 $\rightarrow$ Asn substitution is associated with 
increased resistance to fluoroquinolones [17]. In GyrB, a difference at position 426 was also evidenced between $M$. gallisepticum and $M$. synoviae with an Asn instead of an Asp. The Asp426 $\rightarrow$ Asn substitution has been observed in a mutant of $M$. gallisepticum with a slight increase of resistance $(0.06 \rightarrow 0.125 \mu \mathrm{g} / \mathrm{mL})$ [31].

The detection of a mutation in the ParC QRDR suggests that the parC gene might be the primary target of enrofloxacin in $M$. synoviae as described for M. bovirhinis [16] or Staphylococcus aureus (grlA) [11]. Previous studies have shown Topoisomerase IV to be the primary target of ciprofloxacin (analogous to enrofloxacin) in $M$. hominis [3]. These studies suggest that the preferential target of each fluoroquinolone depends on each bacteria considered. Further studies on $M$. synoviae in vitro-selected mutants should be conducted to confirm this hypothesis.

Some of the re-isolated mycoplasmas with increased enrofloxacin MIC did not have any mutation in the QRDR of the different subunits of the topoisomerases. Mutations elsewhere in the genes coding for DNA gyrase or topoisomerase IV or modifications in drug efflux systems, may contribute to the resistant phenotype of these mutants. Efflux mechanisms have been recently reported in $M$. hominis [30] but have not yet been investigated in other Mycoplasma species.

In conclusion, the results showed that under these experimental conditions, two oral treatments with enrofloxacin were not effective for the eradication of $M$. synoviae. This persistence could be associated with a decrease of the susceptibility level of some re-isolated clones. However this phenomenon is not sufficient to totally explain the M. synoviae persistence. In fact, some reisolated mycoplasmas did not display enrofloxacin MIC change even after two treatments. These observations demonstrated that factors other than antibiotic resistance are probably implicated in mycoplasma persistence.

\section{ACKNOWLEDGMENTS}

We thank Y. Morin (AFSSA) for skilled technical assistance and Claire de Boisséson (AFSSA) for useful advice and technical assistance.

\section{REFERENCES}

[1] Balaban N.Q., Merrin J., Chait R., Kowalik L., Leibler S., Bacterial persistence as a phenotypic switch, Science 305 (2004) 1622-1625.

[2] Bébéar C., Robertson J.A., Determination of minimal inhibitory concentrations, in: Tully J.G., Razin S. (Eds.), Molecular and diagnostic procedures in mycoplasmology, Vol. II: Diagnostic procedures, Academic Press, New York, 1996, pp. 189-197.

[3] Bébéar C.M., Renaudin H., Charron A., Bové J.M., Bébéar C., Renaudin J., Alterations in topoisomerase IV and DNA gyrase in quinolone-resistant mutants of Mycoplasma hominis obtained in vitro, Antimicrob. Agents Chemother. 42 (1997) 2304-2311.

[4] Bébéar C.M., Charron A., Bové J.M., Bébéar C., Renaudin J., Cloning and nucleotide sequences of the topoisomerase IV $\operatorname{parC}$ and parE genes of Mycoplasma hominis, Antimicrob. Agents Chemother. 42 (1998) 20242031.

[5] Bébéar C.M., Renaudin J., Charron A., Renaudin H., de Barbeyrac B., Schaeverbeke T., Bébéar C., Mutations in the gyrA, parC, and $\operatorname{parE}$ genes associated with fluoroquinolone resistance in clinical isolates of Mycoplasma hominis, Antimicrob. Agents Chemother. 43 (1999) 954-956.

[6] Bébéar C.M., Renaudin H., Charron A., Gruson D., Lefrançois M., Bébéar C., In vitro activity of trovafloxacin compared to those of five antimicrobials against mycoplasmas including Mycoplasma hominis and Ureaplasma urealyticum fluoroquinolone-resistant isolates that have been genetically characterized, Antimicrob. Agents Chemother. 44 (2000) 2557-2560

[7] Bradbury J.M., Yavari C.A., Giles C.J., In vitro evaluation of various antimicrobials against Mycoplasma gallisepticum and Mycoplasma synoviae by the micro-broth method, and comparison with a commercially-prepared test system, Avian Pathol. 23 (1994) 105-115.

[8] Chambaud I., Heilig R., Ferris S., Barbe V., Samson D., Galisson F., Moszer I., Dybvig K., Wroblewski H., Viari A., Rocha E.P., 
Blanchard A., The complete genome sequence of the murine respiratory pathogen $\mathrm{Myco}$ plasma pulmonis, Nucleic Acids Res. 29 (2001) 2145-2153.

[9] Combet C., Blanchet C., Geourjon C., Deléage G., NPS@: Network Protein Sequence Analysis, TIBS 25 (2000) 147-150.

[10] Dallo S.F., Baseman J.B., Intracellular DNA replication and long-term survival of pathogenic mycoplasmas, Microb. Pathog. 29 (2000) 301-309.

[11] Ferrero L., Cameron B., Manse B., Lagneaux D., Crouzet J., Famechon A., Blanche F., Cloning and primary structure of Staphylococcus aureus DNA topoisomerase IV: a primary target of fluoroquinolones, Mol. Microbiol. 13 (1994) 641-653.

[12] Forsyth M.H., Sayed A.S., Geary S.J., Sequence and transcriptional analysis of the genes encoding the class-II topoisomerase of Mycoplasma gallisepticum, Gene 163 (1995) 161-162.

[13] Freundt E.A., Culture media for classic mycoplasmas, in: Tully J.G., Razin S. (Eds.), Methods in mycoplasmology, Vol. I. Mycoplasma characterization, Academic Press, New York, 1983, pp. 127-135.

[14] Frey M.L., Hanson R.P., Anderson D.P., A medium for isolation of avian mycoplasmas, Am. J. Vet. Res. 29 (1968) 2163-2171.

[15] Gautier-Bouchardon A.V., Reinhardt A.K., Kobisch M., Kempf I., In vitro development of resistance to enrofloxacin, erythromycin, tylosin, tiamulin and oxytetracycline in $\mathrm{Myc}$ oplasma gallisepticum, Mycoplasma iowae and Mycoplasma synoviae, Vet. Microbiol. 88 (2002) 47-58.

[16] Hirose K., Kawasaki Y., Kotani K., Abiko K., Sato H., Characterization of a point mutation in the parC gene of Mycoplasma bovirhinis associated with fluoroquinolone resistance, J. Vet. Med. B Infect. Dis. Vet. Public Health 51 (2004) 169-175.

[17] Hooper D.C., Mechanisms of fluoroquinolone resistance, Drug Resist. Updat. 2 (1999) 38-55.

[18] Kellog D.E., Kwok S., Detection of human immunodeficiency virus, in: Innis M.A., Gelfand D.H., Sninsky J.J., White T.J. (Eds.), PCR protocols: a guide to methods and applications, Academic Press, San Diego, 1990, pp. 339-343.

[19] Kempf I., Gesbert F., Comparison of serological tests for detection of Mycoplasma gallisepticum antibodies in eggs and chicks hatched from experimentally infected hens, Vet. Microbiol. 60 (1998) 207-213.

[20] Kempf I., Ollivier C., L'hospitalier R., Guittet M., Bennejean G., Concentrations minimales inhibitrices de 13 antibiotiques vis-à-vis de 21 souches de mycoplasmes des volailles, Le Point Vétérinaire 20 (1988) 83-88.

[21] Keren I., Kaldalu N., Spoering A., Wang Y., Lewis K., Persister cells and tolerance to antimicrobials, FEMS Microbiol. Lett. 230 (2004) 13-18.

[22] Kleven S.H., Mycoplasma synoviae infection, in: Barnes H.J., Glisson J.R., Fadly A.M., McDougald L.R., Saif Y.M. (Eds.), Diseases of Poultry, 11th ed., Iowa State University Press, Ames, Iowa, 2003, pp. 756-766.

[23] Knoll U., Glunder G., Kietzmann M., Comparative study of the plasma pharmacokinetics and tissue concentrations of danofloxacin and enrofloxacin in broiler chickens, J. Vet. Pharmacol. Ther. 22 (1999) 239-246.

[24] Ladefoged S.A., Christiansen G., Sequencing analysis reveals a unique gene organization in the gyrB region of Mycoplasma hominis, J. Bacteriol. 176 (1994) 5835-5842.

[25] Marois C., Dufour-Gesbert F., Kempf I., Detection of Mycoplasma synoviae in poultry environment samples by culture and polymerase chain reaction, Vet. Microbiol. 73 (2000) 311-318.

[26] Maxwell A., Critchlow S.E., Chapter 4: Mode of action, in: Kuhlmann J., Dalhoff A., Zeiler H.J. (Eds.), Handbook of experimental pharmacology: Quinolone antibacterials, SpringerVerlag, Berlin, 1998, pp. 120-166.

[27] Much P., Winner F., Stipkovits L., Rosengarten R., Citti C., Mycoplasma gallisepticum: influence of cell invasiveness on the outcome of experimental infection in chickens, FEMS Immunol. Med. Microbiol. 34 (2002) 181186.

[28] Papazisi L., Gorton T.S., Kutish G., Markham P.F., Browning G.F., Nguyen D.K., Swartzell S., Madan A., Mahairas G., Geary S.J., The complete genome sequence of the avian pathogen Mycoplasma gallisepticum strain R(low), Microbiology 149 (2003) 2307-2316.

[29] Piddock L.J.V., Mechanisms of fluoroquinolone resistance: an update 1994-1998, Drugs 2 (1999) 11-18.

[30] Raherison S., Gonzales P., Renaudin H., Increased expression of two multidrug transporter-like genes is associated with ethidium bromide and ciprofloxacin resistance in $\mathrm{Myc}$ oplasma hominis, Antimicrob. Agents Chemother. 49 (2005) 421-424. 
[31] Reinhardt A.K., Bébéar C.M., Kobisch M., Kempf I., Gautier-Bouchardon A.V., Characterization of mutations in DNA gyrase and topoisomerase IV involved in quinolone resistance of Mycoplasma gallisepticum mutants obtained in vitro, Antimicrob. Agents Chemother. 46 (2002) 590-593.

[32] Reinhardt A.K., Kempf I., Kobisch M., GautierBouchardon A.V., Fluoroquinolone resistance in Mycoplasma gallisepticum: DNA gyrase as primary target of enrofloxacin and impact of mutations in topoisomerases on resistance level, J. Antimicrob. Chemother. 50 (2002) 589-592.

[33] Reinhardt A.K., Gautier-Bouchardon A.V., Gicquel-Bruneau M., Kobisch M., Kempf I., Persistence of Mycoplasma gallisepticum in chickens after treatment with enrofloxacin, without resistance development, Vet. Microbiol. 106 (2005) 129-137.

[34] SAS Institute, SAS/STAT user's guide, version 8, SAS Institute Inc., Cary, NC, 1999.

[35] Stanley W.A., Hofacre C.L., Speksnijder G., Kleven S.H., Aggrey S.E., Monitoring Mycoplasma gallisepticum and Mycoplasma synoviae infection in breeder chickens after treatment with enrofloxacin, Avian Dis. 45 (2001) 534-539.
[36] Sumano L.H., Ocampo C.L., Brumbaugh G.W., Lizarraga R.E., Effectiveness of two fluoroquinolones for the treatment of chronic respiratory disease outbreak in broilers, $\mathrm{Br}$. Poult. Sci. 39 (1998) 42-46.

[37] Wang C., Ewing M., Aarabi S.Y., In vitro susceptibility of avian mycoplasmas to enrofloxacin, sarafloxacin, tylosin and oxytetracycline, Avian Dis. 45 (2001) 456-460.

[38] Wang T., Tanaka M., Sato K., Detection of grlA and gyrA mutations in 344 Staphylococcus aureus strains, Antimicrob. Agents Chemother. 42 (1998) 236-240.

[39] Winner F., Rosengarten R., Citti C., In vitro cell invasion of Mycoplasma gallisepticum, Infect. Immun. 68 (2000) 4238-4244.

[40] Yokoyama K., Makino K., Kubota Y., Watanabe M., Kimura S., Yutsudo C.H., Kurokawa K., Ishii K., Hattori M., Abe H., Iida T., Yamamoto K., Hayashi T., Yasunaga T., Honda T., Sasakawa C., Shinagawa H., Complete nucleotide sequence of the prophage VT1-Sakai carrying the Shiga toxin 1 genes of the enterohemorrhagic Escherichia coli O157:H7 strain derived from the Sakai outbreak, Gene 258 (2000) 127-139. 